\title{
Evaux Spring Water-based Topical Spray
}

National Cancer Institute

\section{Source}

National Cancer Institute. Evaux Spring Water-based Topical Spray. NCI Thesaurus. Code C100046.

A skin spray composed of Evaux thermal spring water, the emulsifier polysorbate 20, the preservatives phenoxyethanol and chlorphenesin, zinc gluconate, and the moisturizer caprylyl glycol with prophylactic and calming activity. Evaux thermal spring water is rich in mineral elements particularly of lithium, strontium and mang anese. When sprayed directly onto the skin or scalp, this topical spray may have a calming, moisturizing, healing and nurturing effect. This agent may prevent or decrease skin rashes associated with the administration of EGFR inhibitors or with radiochemotherapy-induced skin reactions. 